Original Research Article

\title{
Causality assessment and the severity of the adverse drug reactions in tertiary care hospital: a pharmacovigilance study
}

\author{
S. G. S. Rajeshreddy V., Lokesh V. Patil*
}

Department of Pharmacology, Karnataka Institute of Medical Sciences, Hubballi, Karnataka, India

Received: 12 October 2017

Revised: 20 October 2017

Accepted: 24 November 2017

*Correspondence to:

Dr. Lokesh V. Patil,

Email: drlokeshpatil@ gmail.com

Copyright: (C) the author(s), publisher and licensee Medip Academy. This is an openaccess article distributed under the terms of the Creative Commons Attribution NonCommercial License, which permits unrestricted noncommercial use, distribution, and reproduction in any medium, provided the original work is properly cited.

\begin{abstract}
Background: Adverse drug reactions (ADRs) constitute a major clinical problem in terms of human suffering and increased health care costs. To study the adverse drug reactions reported in a tertiary care hospital and study of causality as sessment and severity of adverse drug reaction (ADR) cases reported.

Methods: A prospective observational study was conducted as part of pharmacovigilance program over 12months between September 2015 and August 2016. Adverse drug reactions reported from hospital were filled into Suspected ADR - CDSCO forms and submitted to pharmacovigilance unit. Causal relationship was assessed and categorized by Naranjo's algorithm and WHO UMC causality scale. The severity of each ADR was assessed using Modified Hartwig and Siegel scale.

Results: Total 120 cases were reported over 12 months. Among them, $66 \%$ were in males and $55 \%$ were in females. The majority of ADRs were due to antimicrobial agents $(40.78 \%)$ followed by haematinics $(12 \%)$ and anti-epileptics $(10 \%)$. Maximum number of patients $(30.25 \%)$ reported with dermatological manifestations. Highest number of ADRs was reported from the department of medicine $(45 \%)$. As per Naranjo's scale, $54 \%$ reports were assessed as probable and $46 \%$ classified as possible. Majority of cases were mild to moderate in severity.

Conclusions: The pattern of ADRs reported in our hospital is similar with the pattern of studies conducted in other hospitals elsewhere. This study provides a database of ADRs due to commonly used drugs in our hospital, which will help clinicians for their optimum and safe use. Hence effective pharmacovigilance is required for the use of these drugs and their safety as sessment.
\end{abstract}

Keywords: Adverse drug reactions, Causality assessment pharmacovigilance, Spontaneous reporting

\section{INTRODUCTION}

Adverse drug reactions (ADRs) constitute a major clinical problem in terms of human suffering and increased health care costs. ${ }^{1}$ W orld Health Organization (WHO) defines an ADR as any noxious, unintended, and undesired effect of a drug, which occurs at doses used in humans for prophylaxis, diagnosis, or cure of a disease. ${ }^{2}$ ADRs are responsible for 5-11\% of hos pitaladmissions of which 60$70 \%$ are preventable. ${ }^{3,4}$ Spontaneous reporting has contributed significantly to successful pharmacovigilance. ${ }^{5}$ The aim was to study the adverse drug reactions reported in a tertiary care hospital and causality as ses sment and severity of adverse drug reaction (ADR) cases reported with the main objective of creating awareness among the health care professionals and patients on adverse drug reactions and their reporting. The implementation of ADR monitoring based on spontaneous reporting will be useful for the detection and evaluation of ADRs associated with increase in morbidity and duration of hos pitalization.

\section{METHODS}

This was a prospective observational study conducted at ADR monitoring center of Karnataka Institute of Medical Sciences and Hospital, Hubballi, Karnataka. The study 
was carried out over a period of 12 months from September 2015 to August 2016. A total of 120 cases reported over a period of 12 months were included in the study.

\section{Inclusion criteria}

- $\quad$ Patients of all age, both genders, seeking treatment at KIMS Hubballi and developed ADRs.

- Patients willing to give written informed consent.

- Suspected adverse drug reactions reported to the ADR monitoring center

\section{Exclusion criteria}

- Patients who were not willing to participate in the study.

\section{Study procedure}

The suspected adverse drug reactions reported to the pharmacovigilance center were filled into CDSCO spontaneous ADR reporting forms. Causal relationship was assessed and categorized by Naranjo's algorithm and WHO-UMC causality scale. ${ }^{6}$ The severity of each reported ADR was assessed using the criterion developed by modified Hartwig and Siegel scale. ${ }^{7}$ All values were expressed in percentages and depicted using tables and charts.

\section{RESULTS}

A total of 120 ADRs were reported over 12 months. Of these, $55 \%$ were in males and $45 \%$ were in females (Table $1)$.

Table 1: Gender-wise distribution of ADRs.

\begin{tabular}{|lll|}
\hline Gender & Number of cases (120) & Percentage (\%) \\
\hline Male & 66 & $55 \%$ \\
\hline Female & 54 & $45 \%$ \\
\hline
\end{tabular}

Table 2: Department-wise distribution of ADRs.

\begin{tabular}{|lll|}
\hline Department & No. of ADRS & Percentage (\%) \\
\hline Medicine & 54 & 45 \\
\hline Obg & 25 & 20 \\
\hline Surgery & 13 & 10.8 \\
\hline Psychiatry & 8 & 6.7 \\
\hline Dermatology & 7 & 5.8 \\
\hline Pediatrics & 6 & 5 \\
\hline Ent & 3 & 2.5 \\
\hline Ophthalmology & 2 & 1.7 \\
\hline Orthopedics & 2 & 1.7 \\
\hline Total & 120 & 100 \\
\hline
\end{tabular}

Highest number of ADRs reported in the age group of 2130 years of age followed by 41-50 years of age group (Figure 1).

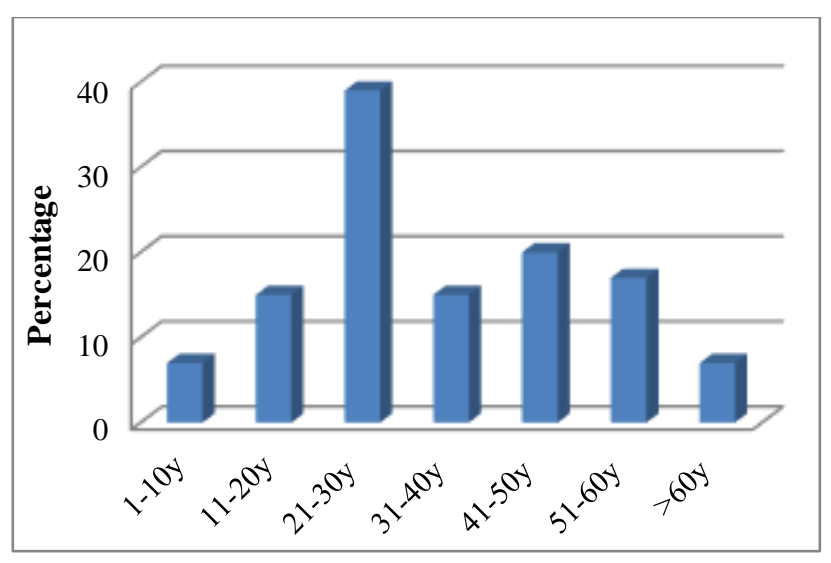

Figure 1: Age wise distribution of ADRs.

Maximum number of cases were reported from the department of medicine (45\%) followed by obstetrics and gynecology $(20 \%)$ and department of surgery $(10.8 \%)$. (Table 2).

Among the suspected drugs causing ADRs, antimicrobial agents (AMAs) accounted for $52 \%$ of the total cases followed by CNS drugs and hematinics which were implicated in $12 \%$ of cases each (Figure 2). The most common adverse drug reactions involved skin and appendages (28\%) and gastrointestinal system (26\%) (Figure 3).

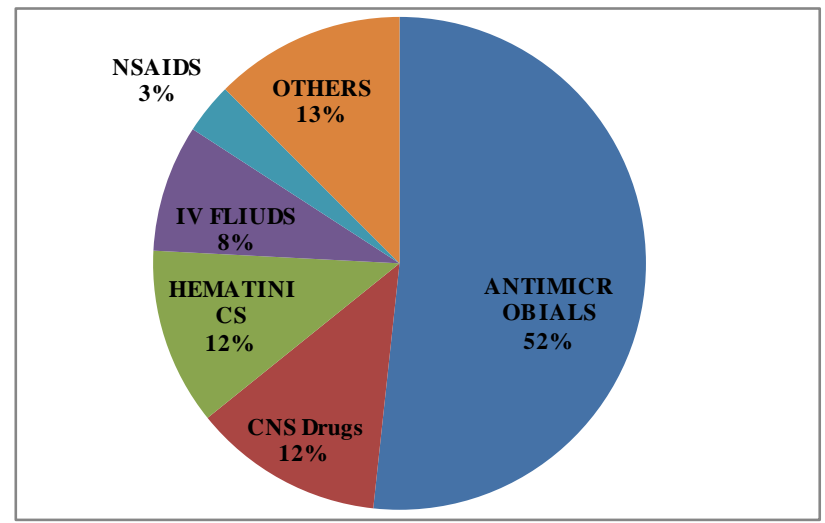

Figure 2: ADRs in various drug classes (\%).

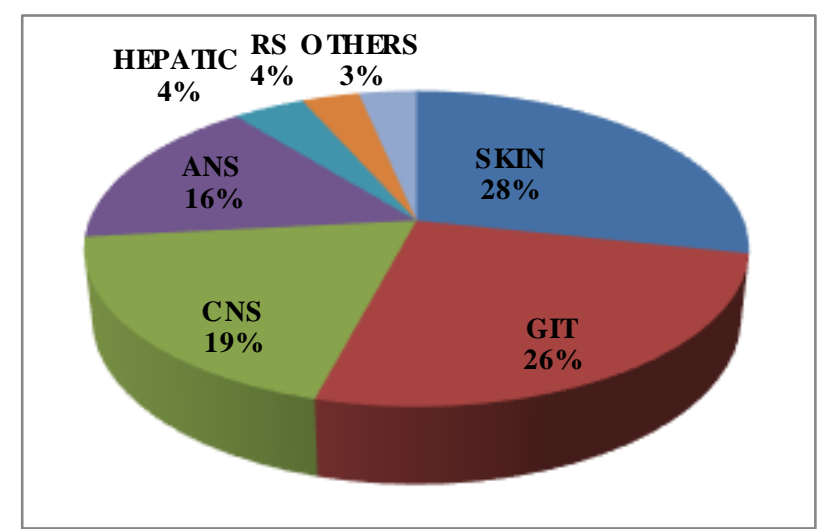

Figure 3: Organ systems involved in ADRs (\%). 


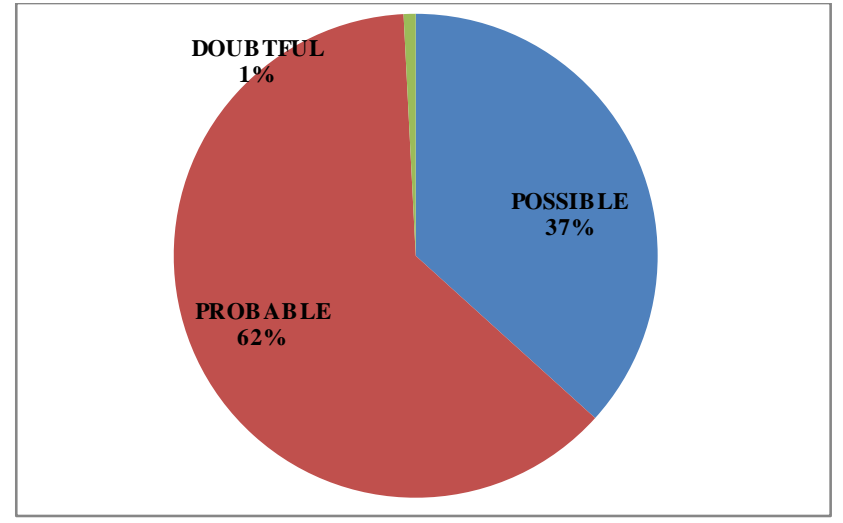

Figure 4: Causality assessment using Naranjo's algorithm.

Assessment of ADRs using Naranjo's causality assessment scale showed that $62 \%$ of ADRs were probable, $37 \%$ were classified as possible and $1 \%$ were unlikely to have occurred due to drug administration (Figure 4). WHO-UMC probability assessment scale revealed that out of 120 cases, $54 \%$ were probable and $45 \%$ were possible/ likely (Table 3 ). Reported ADRs were mainly mild to moderate in severity (Table 4).

Table 3: WHO-UMC assessment scale.

\begin{tabular}{|ll|}
\hline Type of reaction & Percentage (\%) \\
\hline Certain & $0 \%$ \\
\hline Probable/ likely & $54 \%$ \\
\hline Possible & $45 \%$ \\
\hline Unlikely. & $1 \%$ \\
\hline Conditional/ unclassified & $0 \%$ \\
\hline Unassessable/ unclassifiable & $0 \%$ \\
\hline
\end{tabular}

Table 4: Severity assessment by modified hartwig and Siegel scale.

\begin{tabular}{|lll|}
\hline $\begin{array}{l}\text { Type or severity of } \\
\text { ADRs }\end{array}$ & $\begin{array}{l}\text { Number } \\
\text { cases }\end{array}$ & Percentage (\%) \\
\hline Mild & 46 & 38.33 \\
\hline Moderate & 68 & 56.66 \\
\hline Severe & 06 & 5 \\
\hline Lethal & 0 & 0 \\
\hline
\end{tabular}

\section{DISCUSSION}

In our study demographic profile showed that out of 120 cases reported, $55 \%$ were males and $45 \%$ were females which showed similar trend as in the study done by Shrivastava $\mathrm{M}$ et al. ${ }^{8}$ Majority of patients were in the age group of 21-30 years followed by 31-40 years of age group. It could be due to the reason that population of this age group is attending hospital more frequently and receiving drug therapy.

The highest number of cases were reported from the department of medicine which is in accordance with study done by Ponnusankar et al and Murphy B et al. ${ }^{9,10}$ The maximum reports were reported to use of antimicrobial agents (AMAs), which is in accordance with the result of studies done by Murphy B et. al and Lukshmy M Hettihewa et al. ${ }^{10,11}$ The most commonly effected organ system was skin and gastrointestinal tract which is in accordance with other such studies done by Shrivastava $\mathrm{M}$ et al, and Chan AL et al. ${ }^{8,12}$ Rash, itching and nausea, vomiting and gastritis were the most common symptoms presented with and would lead to increased cost of health care and prolong the hospitalstay. ${ }^{13}$

Assessment of the ADRs using Naranjo's scale showed that $67.5 \%$ of cases were classified as probable, $57 \%$ were possible and $1 \%$ of cases were in doubtful category. On assessment of ADRs by using WHO-UMC causality assessment scale the number of certain cases were $0 \%$ as no Dechallenge was done, $54 \%$ were possible/likely, $45 \%$ were possible and $1 \%$ classified as unlikely.

Severity Assessment by Modified Hartwig and Siegel Scale showed that $68(56.66 \%)$ ADRs were moderate, 46 $(38.33 \%)$ ADRs were mild and $6(5 \%)$ ADRs were severe. No lethal effects were produced. Our study provided the database of ADRs due to commonly used drugs and monitoring and detection of such known ADRs by effective implementation of pharmacovigilance and would lead to prevention and better management of ADRs. ${ }^{13,14}$

\section{CONCLUSION}

The pattern of ADRs reported in our hospital is comparable with the results of studies conducted in hospital set up elsewhere. Antimicrobial agents were causing maximu $\mathrm{m}$ ADRs. This study provides a database of ADRs due to common drugs used in our hospital, which will help clinicians for optimum and safe use of these drugs. Hence effective implementation of pharmacovigilance would result in better strict vigilance use of these drugs and their safety assessment which would ultimately result in better patient care.

Funding: No funding sources

Conflict of interest: None declared

Ethical approval: The study was approved by the Institutional Ethics Committee

\section{REFERENCES}

1. Classen DC, Pestotnik SL, Evans RS, Lloyd JF, Burke JP. Adverse drug events in hospitalized patients, Excess length of stay, extra costs and attributable mortality, JAMA. 1997;227(4):301-6.

2. Edwards IR, Aronson JK. Adverse drug reactions: Definitions, diagnosis, and management. Lancet 2000;356:1255-9.

3. Beijer HJ, de Blaey CJ. Hospitalisations caused by adverse drug reactions (ADR): A meta-analysis of observational studies. Pharm World Sci. 2002;24:4654. 
4. Bates DW, Cullen DJ, Laird N, Petersen LA, Small $\mathrm{SD}$, Servi D, et al. Incidence of adverse drug events and potential adverse drug events. Adverse drug event prevention study group. JAMA. 1995;274:29-34.

5. Lexchin J. Is there still a role for spontaneous reporting of adverse drug reactions?. Canadian Medical Association Journal. 2006;174(2):191-2.

6. Naranjo CA, Busto U, Sellers EM, Sandor P, Ruiz I, Roberts EA, et al. A method for estimating the probability of adverse drug reactions. Clin Pharmacol Ther. 1981;30:239-45.

7. Hartwig SC, Siegel J, Schneider PJ. Preventability and severity assessment in reporting adverse drug reactions. Am J Hosp Pharm. 1992;49:2229-32.

8. Shrivastava M, Uchit G, Chakravarti A, Joshi G, Mahatme M, Chaudhari H. Adverse Drug Reactions Reported in Indira Gandhi Government Medical College and Hospital, Nagpur. JAPI. 2011;59:1-4.

9. Ponnusankar S, Tejaswini M, Chaitanya M. Assessment of Adverse Drug Reactions Based on Spontaneous Signals at Secondary Care Public Hospital. Ind J Pharma Sci. 2015;490-3.

10. Murphy BM, Frigo LC. Development, implementation, and results of a successful multidisciplinary adverse drug reaction reporting program in a university teaching hospital, Hosp Pharm. 1993;28(12):1199-204.

11. Hettihewa LM, Sirisena B. Casualty assessment and the severity of the adverse drug reactions (ADR) actively detected in hospital-in patients in tertiary care hospital Sri Lanka: Prospective observational survey. Asian Journal of Research in Biological and Pharmaceutical Sciences. 2014;2(1):1-10.

12. Chan AL, Lee HY, Ho CH, Cham TM, Lin SJ. Cost evaluation of adverse drug reactions in hospitalized patients in Taiwan: A prospective, descriptive, observational study. Curr Ther Res Clin Exp . 2008;69:118-29.

13. Meyboom RH, Linquist M, Egberts AC, Edward IR. Signal selection and follow-up in pharmacovigilance. Drug Saf. 2002;25:459-65.

14. Pirmohamed M, Breckenridge AM, Kitterinham NR, Park BK. Fortnightly review: adverse drug reactions. Brit Med J. 1998;316:1295-8.

Cite this article as: Rajeshreddy SGSV, Patil LV. Causality assessment and the severity of the adverse drug reactions in tertiary care hospital: a pharmacovigilance study. Int J Basic Clin Pharmacol 2017;6:2800-3. 